\title{
Percepção dos médicos do programa "mais médicos": supervisão acadêmica e formação médica na Paraíba
}

\section{Percepcion of doctors of the "more doctors" program: academic supervision and medical training in Paraíba}

DOI: $10.46919 / \operatorname{archv2n3-020}$

Recebimento dos originais: 01/05/2021

Aceitação para publicação: 30/06/2021

\author{
Ana Paula Oliveira da Silva \\ Rua Sérgio Moreira de Figueiredo, S/n - Populares, Cajazeiras - PB, 58935-000 \\ Telefone: (83) 9 9788-2002 \\ E-mail: aposlucas@hotmail.com \\ Cleide Carneiro \\ Av. Dr. Silas Munguba, 1700, Itapepri, Fortaleza-CE, 60914-903 \\ Telefone (85)99619-0676 \\ E-mail: cleide.carneiro@uece.br \\ Antonio Germane Alves Pinto \\ Av. Dr. Silas Munguba, 1700, Itapepri, Fortaleza-CE, 60914-903 \\ Telefone (88)996080-4555 \\ E-mail: germane.pinto@uece.br \\ Heraldo Simões Ferreira \\ Av. Dr. Silas Munguba, 1700, Itapepri, Fortaleza-CE, 60914-903 \\ Telefone (85) 99619-0676 \\ E-mail: heraldo.Simoes@uece.br \\ Antônio Augusto Jordão Ramos \\ Rua Sérgio Moreira de Figueiredo, S/n - Populares, Cajazeiras - PB, 58935-000 \\ Telefone: (87) 98111-5678 \\ E-mail: antonio.jordao@ebserh.gov.br
}

\section{RESUMO}

O presente estudo apresenta-se como um estudo de caso, com abordagem qualitativa sobre a modalidade Supervisão acadêmica para médicos na cidade de Cajazeiras, com o objetivo compreender o processo de supervisão acadêmica. Foram entrevistados nove médicos de diferentes Unidades Básicas de Saúde da cidade, onde se evidenciou grandes potencialidades na qualificação do atendimento na Atenção Primária, apoiando e dando suporte as suas práticas no processo de supervisão e ausência do médico supervisor dentro do território nas visitas domiciliares. É essencial que novos estudos acompanhem esse processo de educação permanente, através da supervisão acadêmica, no sentido de avaliar suas ações e intervenções realizadas dentro do território, voltada para educação médica, uma vez que existem pouquíssimos estudos no decorrer de quase cinco anos de atuação do Programa Mais Médicos, que reportem o trabalho do supervisor acadêmico, para que possíveis qualificações pedagógicas sejam oferecidas aos mesmos.

Palavras-chave: Programa Mais Médicos, Supervisão acadêmica, Atenção primária. 


\section{ABSTRACT}

The present study is a case study with a qualitative approach on academic supervision in the city of Brazil, from the perspective of the doctor supervised, in order to understand the process of academic supervisors were interviewed ten doctors of different basic health units in the city, where he showed great potential in the qualification of care in primary care, supporting and supporting their practices in the process of supervision, but still showed a lack of practice During supervision and pedagogical lack of physician contact supervisor, within the territory, in home visits. It is essential that new studies will accompany this process of permanent education, through academic supervision, in order to evaluate their actions and interventions carried out within the territory for medical education, since there are very few studies in the course of nearly five years of the program more doctors, which report the work of the academic supervisor, for possible pedagogical qualifications are offered to them.

Keywords: More Doctors Progrma, Academic supervision, Primary care.

\section{INTRODUÇÃO}

O Programa Saúde da Família foi implantado no Brasil em 1994 como Política Nacional de Atenção Básica, substituindo o modelo assistencial vigente, centrado no ambiente hospitalar puramente curativo. É reconhecido hoje como Estratégia Saúde da Família (ESF), através da Portaria No 648, de 28 de março de 2006, que estabelece que ESF é a estratégia prioritária para o Ministério da Saúde organizar, expandir, qualificar e consolidar a atenção básica, incluindo ações de prevenção, promoção, recuperação e reabilitação dos agravos e possibilitando o acesso universal e contínuo a serviços de saúde de qualidade ${ }^{1}$.

A ESF deve estar preparada para solucionar a quase totalidade dos problemas mais frequentes que se apresentam no nível dos cuidados primários. Mas não basta essa preocupação quantitativa por mais importante que ela seja nos sistemas de atenção à saúde. É necessário que haja uma preocupação com a qualidade da atenção prestada para que se gere valor para as pessoas usuárias².

O grande problema enfrentado entre municípios brasileiros, principalmente os mais carentes, ao longo da história do Programa de Saúde da Família (PSF) e hoje ESF, foi em fixar profissionais, principalmente médicos, a estas equipes para aprimorar a Atenção Básica, o que vem aumentando os problemas nas redes de urgência e emergência que têm sofrido um tumulto enorme por demanda excessiva de usuários procurando essa rede para tratamento de problemas crônicos ou seguimento de doenças, que seriam de competência da Atenção Básica, a qual de acordo com sua proposta é para resolver $80 \%$ dos casos atendidos. O Brasil além de enfrentar um número insuficiente de médicos para atender a população que é1,8\%1000hab ${ }^{3}$, estes se encontram mal distribuídos nas regiões brasileiras.

Ao longo de 30 anos da criação do Sistema Único de Saúde (SUS), foram elaboradas Políticas Nacionais de Atenção Básica (PNAB), uma em 2006 e outra em 2011, onde a de 2006 mudou o conceito de Programa para Estratégia Saúde da Família e consolida esta como estratégia prioritária para Atenção Básica no Brasil, reafirmando ainda o apoio do governo federal na formação de pessoal para Atenção 
Básica com a educação Permanente em Saúde e a de 2011 que reafirmou a importância do Núcleo de Apoio a Saúde da Família (NASF) nas intervenções e resoluções de problemas dentro dos territórios de abrangência da Estratégia de Saúde da Família, possibilitou 8 horas de carga horária semanal dos membros das equipes de Saúde da Família fossem utilizadas com atividades de capacitação profissional, tornando possível, ainda, adequações na carga horária do médico, o qual poderia ficar 20 ou 30 horas, ou até dois médicos em cada Unidade Básica de Saúde (UBS), com repasses financeiros proporcionais, para suprir a dificuldade de fixar médicos nas Unidades Básicas, principalmente no interior do Brasil.

Apesar de reformulações das Políticas de Atenção Básica a gestão da Atenção Básica é exercida pelos municípios, os quais utilizam os recursos direcionados para esta, de forma singular e nem sempre comprometida e responsável, além dos poucos recursos disponíveis, principalmente em municípios pequenos e pobres de regiões mais carentes do Brasil, o que se fez persistir os problemas na fixação de profissionais médicos na ESF.

Em 2013 o Brasil cria o Programa Mais Médicos para o Brasil (PMMB), através da Medida Provisória N$^{\circ} 621$ de 08 de julho de 2013 que é regulamentada em outubro do mesmo ano pela Lei 12.871 na tentativa de suprir uma deficiência e má distribuição histórica de médicos em municípios brasileiros e oferecer atenção básica de qualidade, fazendo também um acordo com a Organização Panamericana de Saúde (OPAS) para trazer profissionais cubanos e preencher as vagas, as quais não teriam sido ocupadas por médicos brasileiros.

Esses médicos são inseridos em uma equipe multiprofissional na Atenção primária e, obrigatoriamente, têm que participar das atividades de aperfeiçoamento integrando ensino e serviço e serem acompanhados por profissionais médicos de instituições fiscalizadoras que apoiam e orientam o processo de educação permanente. Então o eixo desse programa atende, de forma emergencial, as vagas solicitadas pelos municípios que fazem a adesão, além de ampliar e qualificar a formação de médicos, através do aumento do número de vagas de graduação em medicina e aumento nas vagas de residência médica em Medicina de Família e Comunidade e promover melhorias na infraestrutura das UBS.

Apesar do enorme impacto positivo com o aumento do número de médicos nas Unidades Básicas de todo o Brasil, o maior eixo do Programa Mais Médicos não é o provimento de vagas e sim a formação médica. O Programa Mais Médicos proporciona mudanças nas Diretrizes Curriculares Nacionais do curso de Medicina, em 2014, que reformula o currículo médico e determina que 30\% do internato (que deve ser 02 anos da formação) aconteça na Atenção Básica e nos serviços de urgência e emergência do SUS.

Mesmo conhecendo as reais necessidades do SUS e se percebendo as flexibilizações que vêm sendo feitas nas escolas médicas em seus Projetos Políticos-Pedagógicos, os quais vem adequando os cenários de práticas as prioridades e problemas locais, há de se considerar que grande parte dos profissionais que está trabalhando na atenção básica não teve sua formação acadêmica pautada na 
integralidade da saúde, longitudinalidade do cuidado e construção de vínculos com a comunidade a qual assiste, o que se exige um processo eficaz de transformação de práticas através de formação continuada e metodologias que problematizem a realidade vivenciada em sua prática diária. A proposta do Programa Mais Médicos é capacitar os profissionais, que mesmo estando há anos ou não na Atenção Primária, precisa modificar suas práticas, de forma a responsabilizar-se no cuidado integral, transformador, com vínculos entre famílias, intervenções específicas em seus territórios e singularidade de condutas.

A política de educação permanente é uma das prioridades do Programa Mais Médicos, fortalecida pela integração ensino-serviço, para que desenvolvam uma atenção à saúde de qualidade por meio da Universidade Aberta do SUS (UNA-SUS) e Universidades que compõem a rede, incluindo também a supervisão acadêmica por profissionais médicos, os quais são indicados pelas instituições de ensino supervisoras e que totalizam 74, com cerca de 200 tutores e 2000 supervisores fazendo visitas in loco a cada um desses profissionais. Os médicos que atuam no programa fazem uma especialização em atenção primária, com atividades de pesquisa e cumprem uma carga horária de 40 horas semanais, dentre as quais, 8 horas são dedicadas ao ensino e pesquisa ${ }^{4}$.

A formação médica no Brasil vem sendo alvo de discussão permanente, frente as necessidades do SUS, onde profissionais precisam ser reflexivos e críticos sociais perante a realidade vivida em sua prática. A necessidade do olhar clínico diferenciado para cada indivíduo, com responsabilização, intervenção e resolução deve ser exigência do perfil médico perante as demandas de saúde no Brasil ${ }^{4}$. Portanto, é papel do supervisor, transformar as práticas e habilitar competências profissionais que atendam às necessidades e qualidades no atendimento médico dentro da Atenção Primária, exigindo ainda cumprimento de carga horária e apoio do gestor municipal as ações propostas pelo Programa Mais Médicos.

A transformação de práticas médicas dentro do SUS é algo emergente e urgente e que com o Programa Mais Médicos dá uma enorme visibilidade, tanto é que é o maior eixo estruturante desse Programa, o que justifica o estudo em questão, frente ao processo de supervisão acadêmica como parte da educação permanente oferecida aos médicos inseridos.

Assim, o presente estudo tem por objetivo analisar o processo de supervisão acadêmica para formação médica no Programa Mais Médicos, na visão dos médicos supervisionados.

\section{MÉTODO}

Trata-se de uma pesquisa de abordagem qualitativa, do tipo estudo de caso, realizada com os médicos vinculados ao Programa Mais Médicos no município de Cajazeiras, Paraíba, Brasil. Foram selecionados todos os dez médicos, os quais integram as equipes da atenção básica municipal de um total de 23 equipes, entre equipes rural e urbana. Destes, um médico se negou a participar da pesquisa. 
A coleta de dados foi realizada por meio da aplicação de entrevistas gravadas e seguindo um questionário semiestruturado com perguntas abertas. A análise de dados foi feita pela análise de conteúdo, seguindo as etapas propostas por Bardin: pré-análise; exploração do material ou codificação; tratamento dos resultados, inferência e interpretação ${ }^{5}$.

O estudo seguiu as orientações da Resolução no 466112 do Conselho Nacional de Saúde, sendo o projeto aprovado pelo Comitê de Ética em Pesquisa da Universidade Estadual do Ceará sob CAAE $n^{\circ}$ 84270017.6 .0000 .5534

\section{RESULTADOS E DISCUSSÃO}

Os participantes distribuem-se entre médicos brasileiros e médicos cubanos, dentre os quais oito são cubanos e um é brasileiro, sendo a maior parte do sexo feminino. $\mathrm{O}$ ano de formação profissional variou entre 1987 a 2012, em que todos afirmaram ter experiência de atuação da atenção básica, com um período mínimo de quatro anos e máximo de trinta anos. Dentre os médicos cubanos, todos têm especialização em Medicina de Família.

Ao investigar supervisão acadêmica entre esses profissionais no PMMB, emergiram sete categorias: Ruptura no processo de aprendizagem em decorrência das mudanças de supervisor; Contribuição da supervisão acadêmica para o processo de trabalho na atenção básica; Formas de suporte acadêmicoprofissional por parte do supervisor; Estratégias didático-pedagógicas utilizadas para a construção de intervenções no território; Avaliação da aprendizagem ao longo do PMMB; A frequência de supervisões para a fundamentação do processo de aprendizagem; A interação com o supervisor durante o processo de trabalho.

\subsection{CATEGORIA I - RUPTURA NO PROCESSO DE APRENDIZAGEM EM DECORRÊNCIA DAS MUDANÇAS DE SUPERVISOR}

Mediante a análise das falas, observa-se que os médicos consideraram as mudanças recorrentes de supervisor como algo negativo e que gera a ruptura no processo de aprendizagem:

Desde que entrei no Programa já tive três supervisores. Estou com a última há 10 meses e ela é ginecologista. (M1)

Estou com o mesmo supervisor desde que entrei e ela é ginecologista, creio que mudanças de supervisores atrapalham [aprendizagem]. (M2)

Estou com o mesmo supervisor desde que entrei e ela é ginecologista. (M3)

Já tive dois supervisores, o último está comigo há dois anos e é ginecologista. Acredito que a mudança de supervisor atrapalha a minha aprendizagem por desconstrução de vínculos entre territórios. (M4)

Já tive três supervisores e o último está comigo há 01 ano e é ginecologista. As mudanças interferem na aprendizagem, porque diminui a relação e interação. (M5) 
Já tive dois supervisores, o último está comigo há 01 ano e é Otorrinolaringologista. Essa mudança atrapalha porque cada um cumpre um cronograma diferente de trabalho e de repente muda-se tudo. (M6)

Só tive um supervisor. (M7)

A maioria dos médicos, quando interrogados sobre quantos supervisores tiveram, afirmou que desde que estão no Programa Mais Médicos está com o mesmo supervisor, quatro afirmaram ter tido mais de um supervisor e dentre esses, dois tiveram três supervisores. Apontaram a troca de supervisor como rotura no processo de aprendizagem e vínculo em seus respectivos territórios.

No decorrer do Programa Mais Médicos acontecem mudanças nos planos de trabalhos dos supervisores, normalmente quando supervisores desistem de suas atividades e são substituídos por novos médicos e isso, quando acontece, são feitas adequações entre distância dos locais de residência dos novos supervisores e os municípios a serem supervisionados, já que as supervisões acontecem in loco, e em sua maioria, os professores não residem no município em que supervisionam. Com isso, médicos ganham novos supervisores, o que segundo os médicos entrevistados, têm causado certa fragmentação no seu processo de aprendizagem e construção de diagnóstico territorial iniciado com seu supervisor anterior, uma vez que já estavam adaptados a forma de trabalho e o vínculo gerado entre suas relações e seus territórios, que vinham sendo construídos se perdem para um novo recomeço.

O reconhecimento das vulnerabilidades presentes em cada território é essencial para o planejamento das ações interventivas. Portanto é um processo estruturado ao longo do acompanhamento contínuo. E essa construção deve ser carreada entre médico e supervisor ao longo das supervisões in loco para o desenvolvimento de ações elaboradas para estes fins. As trocas de supervisores fragmentam essa estruturação, prejudicando um processo em andamento, os quais foram considerados por parte dos médicos entrevistados, sobretudo entre aqueles que tiveram mais de um supervisor.

\subsection{CATEGORIA II - CONTRIBUIÇÃO DA SUPERVISÃO ACADÊMICA PARA O PROCESSO DE TRABALHO NA ATENÇÃO BÁSICA}

Os profissionais entrevistados relataram que a supervisão acadêmica representava uma importante ferramenta para o processo de trabalho na atenção básica, destacando-se a educação continuada por meio da atualização acerca dos protocolos da $\mathrm{AB}$ e discussão de casos.

Tem me ajudado bastante a me atualizar com relação aos protocolos de atendimentos médicos. (M1)

Contribui me atualizando dos critérios e protocolos utilizados na atenção básica. (M2)

[...] tem uma melhor interação entre profissionais de diferentes países e especialidades, além de nos atualizar quanto aos protocolos de trabalho. (M3)

Tem aumentado meu grau de conhecimento e abordagem de conteúdo. (M4)

A supervisora sempre tem explica dos protocolos de atendimento e esclarece as minhas dúvidas. (M5) 
Sempre com meus dois supervisores, ficamos discutindo casos clínicos e estratégias de trabalho para melhoria do desempenho e assistência a população do meu território. (M6) Eu e meu supervisor ficamos discutindo muitos casos clínicos que tenho visto no cotidiano, inclusive novas formas de tratamento e diagnóstico de doenças desconhecidas em meu país. (M7) Além de participar das consultas, o supervisor tem me dado suporte nas minhas dúvidas. (M8) Meu supervisor está sempre à disposição para tirar dúvidas. (M9)

A supervisão acadêmica, em todas as suas modalidades, do ponto de vista dos médicos do Programa Mais Médicos tem contribuído para melhora no processo de trabalho na Atenção Básica, com intervenções técnicas em seus territórios, revisão e práticas de protocolos utilizados pelo Ministério da Saúde e fortalecimentos de suas ações práticas. Para os médicos cooperados cubanos, além do que foi descrito, têm ensinado a diagnosticar e tratar doenças não conhecidas em seu país e bastante prevalentes no Brasil.

Para Almeida ${ }^{6}$, a supervisão acadêmica se apresenta como importante estratégia de educação permanente em Saúde, extremamente necessária no âmbito do SUS.

A educação permanente é a definição pedagógica para o processo educativo em serviço que possibilita construir espaços coletivos para a reflexão e a avaliação do sentido dos atos produzidos no cotidiano, pondo o cotidiano do trabalho em análise, tanto a incorporação acrítica de tecnologias materiais, como a eficácia da clínica produzida, os padrões de escuta, as relações estabelecidas com os usuários e entre os profissionais ${ }^{7}$.

Almeida et al. ${ }^{6}$ estudando as temáticas trabalhadas pelos supervisores, através de uma análise documental com dados obtidos no Web/portfólio/UNA-SUS, revela que as temáticas mais utilizadas nos encontros de supervisão foram aquelas relacionadas as doenças crônicas não transmissíveis, doenças tropicais negligenciadas, saúde mental e processo de trabalho na Atenção Básica, o que demonstra como a supervisão acadêmica tem contribuído no crescimento da organização e desenvolvimento clínico.

É uniforme como a supervisão acadêmica tem sido apoiadora para os médicos do Programa Mais Médicos, seja participando das consultas, esclarecendo dúvidas como na discussão de casos clínicos, o que nos leva a considerar que a supervisão acadêmica tem sido bastante formativa, porém restrita a atuação médica, enquanto clínico, devendo ser notado que o Médico de Família deve ter capacidade não só terapêutica, mas também de resolver problemas, capacidade preventiva e gestora. Resta estender essas ações formativas para o fortalecimento da prevenção, educação e movimentação em toda abrangência territorial e não somente ações clínicas pontuais.

\subsection{CATEGORIA III - FORMAS DE SUPORTE ACADÊMICO-PROFISSIONAL POR PARTE DO SUPERVISOR}

A maior parte dos médicos citou que as visitas in loco e as locorregionais eram suficientes para que o supervisor pudesse ofertar o suporte acadêmico-profissional necessário. Contudo, dois profissionais 
sugeriram a realização de visitas domiciliares e de palestras educacionais, juntos com seus supervisores para maior conhecimento de respectivos territórios e um médico sugeriu mais de uma locorregional no mês, referindo a mesma como espaço de ampla aprendizagem e trocas de conhecimento.

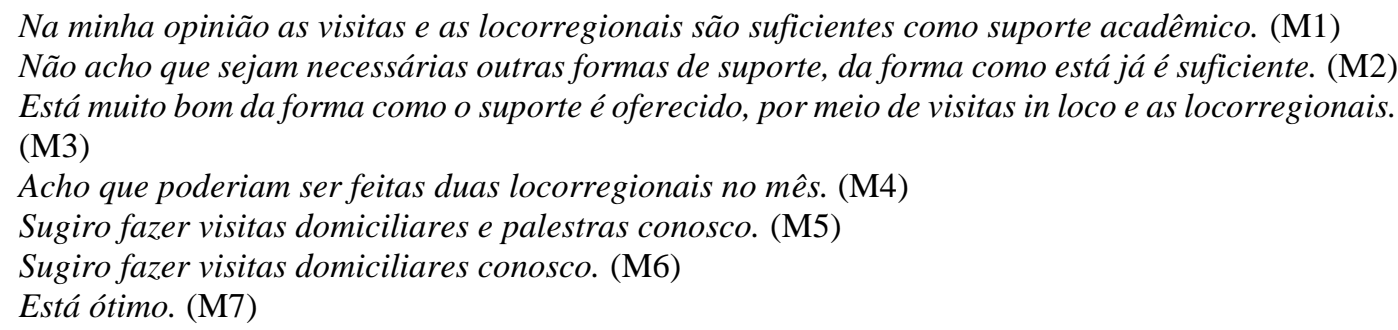

A maioria dos médicos quando questionados sobre a forma como tem recebido suporte acadêmico por parte de seus supervisores e se tinham algo a sugerir para melhorar esse processo, referiram que tem sido suficiente as visitas, as locorregionais e os contatos com seus supervisores, no entanto dois médicos acharam que o médico supervisor deveria fazer visita domiciliar em suas companhias para maior conhecimento de território e um médico acha que as locorregionais deveriam ser com maior frequência por representar um espaço de maior crescimento profissional, uma vez que as práticas são compartilhadas com todos os supervisores e tutores.

As reuniões locorregionais têm se apresentado como encontros de trocas de experiências entre profissionais, onde se discutem temáticas propostas e todos expressam opiniões e percepções, o que gera compartilhamento de saberes técnicos pertinentes ao trabalho na Atenção Primária.

Lima et al. ${ }^{8}$ destacam a importância de organizar o trabalho no âmbito do programa a partir das necessidades reportadas por supervisores e médicos e defende que, se este trabalho primar pela sustentação do conceito à oferta de serviços médicos, ao atendimento a doenças prevalentes e tratamentos pontuais e, sobretudo, contemplar o debate sobre modos de organização o ampliado de saúde, deve contemplar abordagens à atividade clínica e organização social. Logo, as atividades executadas entre profissionais médicos e supervisores devem ser planejadas a partir das demandas destes em seus territórios.

As visitas domiciliares (VD) fazem parte do trabalho de profissionais da Atenção Básica, os quais contextualizam relações com os usuários que fazem entender. A VD é constituída por um conjunto de ações sistematizadas para viabilizar o cuidado de saúde à comunidade, família e indivíduo, bem como para realizar atividades vinculadas aos programas de saúde 9 . 


\subsection{CATEGORIA IV - ESTRATÉGIAS DIDÁTICO-PEDAGÓGICAS UTILIZADAS PARA A CONSTRUÇÃO DE INTERVENÇÕES NO TERRITÓRIO}

Dentre as estratégias didático-pedagógicas utilizadas para a construção de intervenções no território, destacaram-se as palestras e a discussão de casos clínicos, conforme expresso nos trechos a seguir:

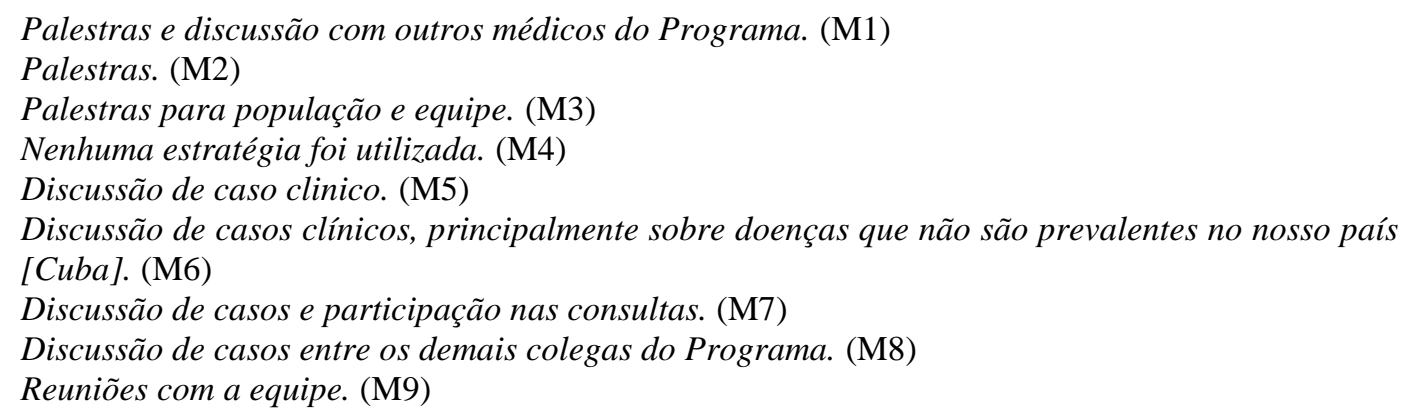

Dentre as estratégias didático-pedagógicas ofertadas durante as supervisões destaca-se as discussões de casos clínicos e palestras entre equipes em territórios. Uma vez que o processo de trabalho na Atenção Básica depende da superação de problemas existentes em seus territórios, das mais diversas apresentações e singularidades, o compartilhamento de problemas e discussão de soluções entre toda a equipe faz parte de uma movimentação constante na qualificação de ações que devem ser revistas diariamente no sentido de promover melhor qualidade no serviço ofertado.

Daí, reforçar aqui a importância dessas ações, unindo forças, indagações e estabelecendo o cuidado continuado e intervenções para melhoria da saúde dentro do território. Ainda sobre trocas estabelecidas nessas reuniões de equipe, cabe salientar nessa coletividade, a riqueza de trocas culturais entre médicos cubanos e equipe brasileira.

O Brasil e outros países, apesar de contextos e estratégias diferentes, compartilham os princípios básicos de que as necessidades sociais e de saúde das comunidades devem guiar os programas de ensino, pesquisa e serviço ${ }^{10}$.

A discussão de casos clínicos entre supervisores e médicos supervisionados fortalece a prática clínica, a tomada de decisões, o questionamento de condutas, a troca de experiências práticas no cuidado à saúde, bem como no compartilhamento de responsabilidade sobre o paciente, partindo-se do pressuposto do reconhecimento das limitações pessoais e profissionais e a existência da dúvida.

A aprendizagem baseada em problemas (Problem-Based Learning - PBL) tem sido reconhecida mundialmente como uma abordagem instrucional capaz de promover a aquisição de conhecimentos pelos alunos ao mesmo tempo em que os ajuda a desenvolver habilidades e atitudes profissionais desejáveis ${ }^{11}$.

A aprendizagem baseada em problemas é uma estratégia renovadora e potente no processo de ensino-aprendizagem com a prática de situações-problemas permitindo o raciocínio clínico, crítico e 
autônomo eficaz no desenvolvimento das práticas em saúde. Portanto, a discussão de casos clínicos é uma potente ferramenta de fortalecimento das condutas clínicas e abordagens sociais na Atenção Básica, tendo em vista que as discussões envolvem todo o contexto social onde o usuário está inserido.

\subsection{CATEGORIA V - ANÁLISE DA APRENDIZAGEM AO LONGO DO PMMB}

Em relação a análise da aprendizagem ao longo do PMMB, todos os médicos consideraram como sendo satisfatória e que contribuiu para o crescimento pessoal e profissional. Além disso, também foi referido que esse crescimento não se restringia apenas aos entrevistados, abrangendo também os próprios supervisores:

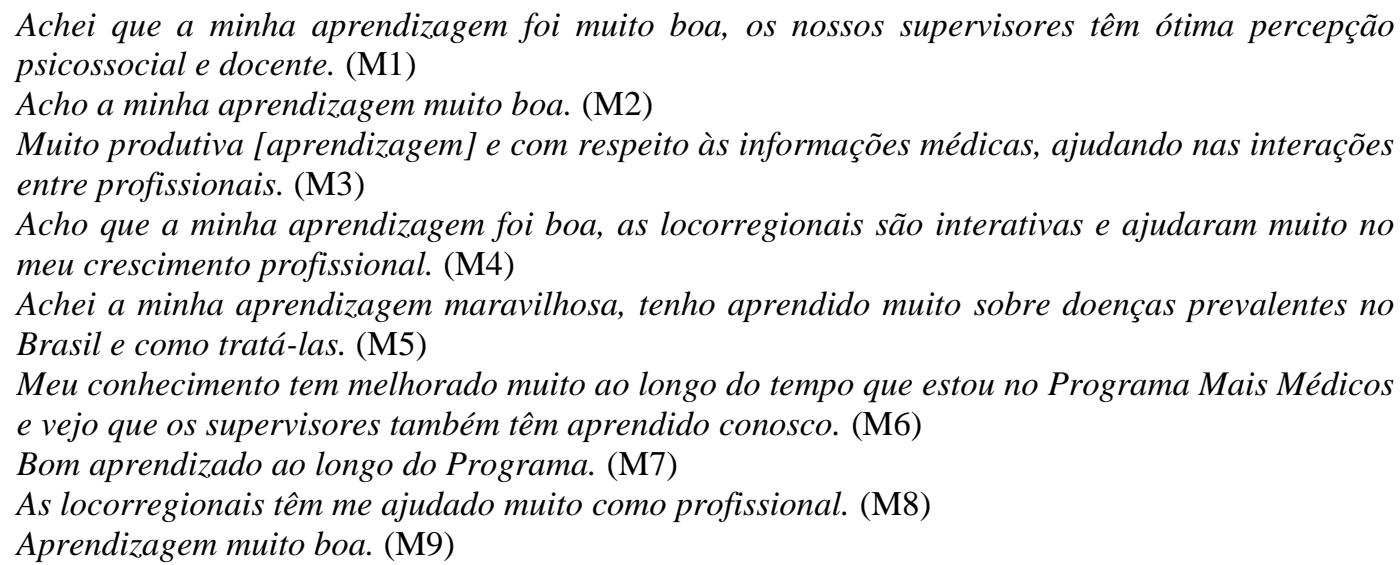

Ao analisar a aprendizagem através da supervisão acadêmica todos os médicos consideram melhora em suas práticas na Atenção Básica, relevando a importância dos espaços de aprendizagem oferecidos pelas locorregionais, como ambiente de interação, trocas e apoio clínico e o suporte individual do supervisor nas visitas em território, além dos contatos por telefone ou e-mail.

A Educação Permanente em serviço é importante tanto para o desenvolvimento de habilidades clínicas, quanto na diversidade de competências trazendo impactos positivos que poderão ser avaliados com mais estudos, com a continuidade da formação dentro do Programa Mais Médicos.

Os conhecimentos adquiridos e produzidos, portanto, serão sempre contextualizados para cada situação específica, sendo, portanto, provisórios, assumindo um cotidiano de ação e reflexão ${ }^{12}$.

\subsection{CATEGORIA VI - A FREQUÊNCIA DE SUPERVISÕES PARA A FUNDAMENTAÇÃO DO PROCESSO DE APRENDIZAGEM}

A maioria dos profissionais consideraram a frequência com que acontecem as supervisões como sendo suficiente para a fundamentação do processo de aprendizagem. Todavia, um dos médicos afirmou que poderia ser realizada mais de uma locorregional por mês, para permitir maior compartilhamento de 
práticas e outro sugeriu mais de uma visita in loco para problematizar mais as adversidades dos usuários adscritos no território e proporcionar uma maior compreensão acerca dos problemas prevalentes na comunidade:

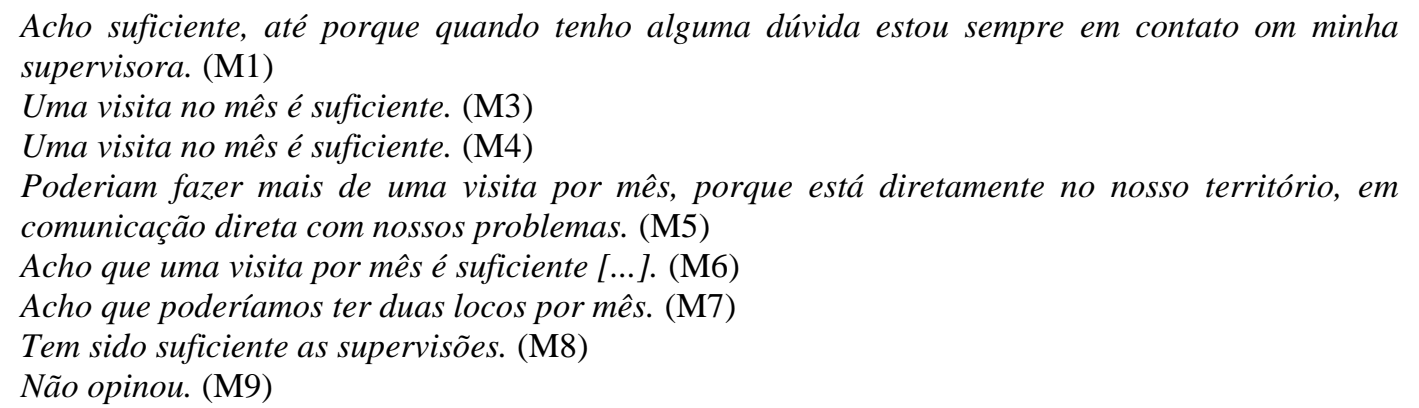

O MEC determina que seja feita uma visita mensal deixando o supervisor a vontade para utilizar esse momento de forma singular para cada supervisionado, de maneira a diagnosticar situações, fazer interconsultas, criar espaços com as equipes e construir percepções concretas que atendam às necessidades dos usuários e fortaleça o potencial técnico do médico de modo a compreender o complexo cenário comunitário.

Ao referirem que os momentos de apoio de preceptoria têm sido suficientes, acredita-se, não que a aprendizagem seja absoluta, mas que os momentos têm sido construtivos e que os recursos utilizados pelo supervisor estão sendo significativos, levando-se em conta também a experiência dos médicos supervisionados na Atenção Primária, pois todos referem experiência prévia, antes de entrarem no Programa, o que ajuda na construção de viabilidades.

A reprodução do conhecimento é contextualizada a partir do fortalecimento que os encontros promovem, sejam presenciais ou a distância, o que produz um conteúdo em crescente movimento e reflexão.

\subsection{CATEGORIA VII - A INTERAÇÃO COM O SUPERVISOR DURANTE O PROCESSO DE TRABALHO}

A interação com o supervisor durante o processo de trabalho foi considerada como satisfatória, haja vista que os profissionais mantêm contato direto ou indireto com o preceptor, o qual está sempre à disposição para auxílio no que for necessário:

Estou sempre em contato com minha supervisora. (M1)

Eu sempre me comunico pelo WhatsApp, e-mail e telefone. (M3)

Sim, estou sempre em contato. (M4)

Nos comunicamos sempre. (M5)

Eu estou sempre em contato com minha supervisora tirando dúvidas, sempre ao telefone, e a mesma está sempre à disposição. (M6)

Meu contato com minha supervisora é constante. (M7) 
Boa interação com minha supervisora. (M8)

Mantenho bom contato com minha supervisora, sempre que preciso. (M9)

O relacionamento entre supervisores e médicos supervisionados mostrou-se interativo e presente por parte de todos os médicos entrevistados, o que contribui para a horizontalização do convívio entre os mesmos, construindo relações de afeto e respeito mútuo.

O vínculo amplia a confiança, segurança e potencializa os espaços para construção de intervenções coletivas, proporcionado pelas trocas entre médico e supervisor. Traz responsabilização mútua e aproximação entre profissionais, que juntos, criam possibilidades para as práticas curativas e preventivas dentro de seus territórios, aumentando assim, a eficácia das ações.

A relação entre preceptor e educando é um importante instrumento para a descoberta do trabalho coletivo. Para que isto aconteça, é importante aceitar e valorizar o que o educando traz enquanto conhecimento teórico e sentimentos ${ }^{13}$.

O preceptor desenvolve o ato da crítica amorosa e cuidadora, sem a perspectiva de inferiorizar o estudante. A relação se horizontaliza quando o preceptor não é nem pretende ser a voz da verdade. Fogese, portanto, da educação bancária, na qual o estudante é depositário do saber do preceptor ${ }^{14}$.

É importante que o preceptor ressalte questões inerentes a todos os atos de saúde, desde as atividades de educação popular à prescrição dos medicamentos, tornando-as alvo de estudo pelos educandos ${ }^{15}$.

\section{CONCLUSÃO}

A supervisão acadêmica no PMMB mostra-se como importante ferramenta de educação permanente sob o ponto de vista dos médicos supervisionados no município de Cajazeiras, onde foi bastante valorizado o vínculo entre médico e supervisor, uma relação horizontal que possibilita liberdade para construções de intervenções e abertura para diálogos, o que contribui na qualificação médica e corresponsalização do cuidado.

Quanto às atividades pedagógicas utilizadas durante a supervisão foi reportado sobre discussão de casos clínicos entre médicos e palestras com as equipes, o que reproduz o aprender fazendo e singularizando as particularidades dos territórios, de forma a contextualizar também as dificuldades encontradas em cada local. Mas houve médico que referiu que seu supervisor não usou qualquer ferramenta pedagógica durante a supervisão, o que se pode questionar a qualificação profissional do supervisor quanto a formação pedagógica para atuar enquanto supervisor e vivências e/ou experiências na Atenção Básica a serem compartilhadas com médico e equipe, o que deve ser vencida dentro desse processo de qualificação das práticas, enquanto Programa Mais Médicos, além de atividades que contemplem atividades preventivas.

Havendo ainda, sugestões do supervisor atuar junto com os médicos nas visitas domiciliares, fazendo diagnóstico de problemas dentro do território para intervenções conjuntas, remete que a supervisão 
ainda seja limitada à clínica, devendo-se rever a abrangência da supervisão para dentro do território, conhecendo as reais necessidades dos usuários, para assim, oferecer suporte terapêutico clínico, preventivo, gerenciador e resolutivo de problemas, o que se exige da Medicina de Família e Comunidade.

Dentre os supervisores, observou-se as especializações em ginecologia, pediatria e otorrinolaringologia e quanto aos médicos supervisionados, os cubanos têm uma formação em Medicina General Integral, que é a Medicina de Família aqui no Brasil,podendo significar diversificações de experiências a serem divididas, tanto in loco, quanto nas locorregionais. Todos os médicos supervisionados referem experiências prévias na Atenção Básica antes de ingressarem no PMMB, o que possibilita maior habilidade em lidar com os complexos movimentos e dinâmicas de um território, em que as questões sociais a serem enfrentadas e dribladas desafiam o cotidiano de qualquer profissional na Atenção Primária.

Como limitação ou fragilidade da atividade de supervisão foi reconhecida a pouca abrangência da supervisão para o território, faltando as visitas domiciliares e as atividades acadêmicas voltadas para as habilidades preventivas, mesmo representando potente ferramenta de educação permanente. 


\section{REFERÊNCIAS}

1. Ministério da Saúde (BR). Política Nacional de Atenção Básica [Internet]. 2006 [acessado 2018 Mai 12]. Brasília: Ministério da Saúde, 2016. Disponível em:

http://bvsms.saude.gov.br/bvs/saudelegis/gm/2017/prt2436_22_09_2017.html

2. Mendes EV. As redes de atenção à saúde [Internet]. 2011 [acessado 2018 Mai 17]. Brasília, Organização Pan-Americana da Saúde, 2011. Disponível em: https://www.paho.org/bra/index.php?option=com_docman\&view=download\&category_slug=servicossaude-095\&alias=1402-as-redes-atencao-a-saude-2a-edicao-2\&Itemid=965

3. Organisation for Economic Co-operation and Development (OECD). Education at a Glance 2011: OECD Indicators [Internet]. 2011 [cited 2018 Jun 07]. OECD Publishing. Available from: https://www.oecd.org/education/skills-beyond-school/48631582.pdf

4. Ministério da Saúde (BR). Secretaria de Gestão do Trabalho e da Educação na Saúde. Programa mais médicos - dois anos: mais saúde para os brasileiros [Internet]. Ministério da Saúde, Secretaria de Gestão do Trabalho e da Educação na Saúde. 2015 [acessado 2018 Jun11]. Brasília: Ministério da Saúde, 2015. Disponível em: http://bvsms.saude.gov.br/bvs/publicacoes/programa_mais_medicos_dois_anos.pdf

5. Bardin L. Análise de conteúdo. São Paulo: Edições 70, 2011.

6. ALMEIDA, E. R. et al. More Doctors in Brazil Project: an analysis of Academic Supervision. Interface (Botucatu) [Internet]. 2017 [acessado 2018 Jun 18]; 21(supl 1): 5-8.

7. Ceccim RB, Capozzolo AA. Educação dos profissionais de saúde e afirmação da vida: a prática clínica como resistência e criação. In: Marins JJN (Org.). Educação médica em transformação: instrumentos para a construção de novas realidades. São Paulo: Hucitec, 2004. Disponível em: http://www.scielo.br/pdf/icse/v21s1/en_1807-5762-icse-1807-576220160558.pdf

8. Lima RCGS, Gripa DW, Prospero ENS, Ros MA. Academic tutorship of the Médicos para o Brasil (More Doctors to Brazsil) Project in Santa Catarina: the ethical-political viwepoint. Ciênc Saúde Colet [Internet]. 2016 [acessado 2018 Mai 02];21(9):2797-805. Disponível em: http://www.scielo.br/pdf/csc/v21n9/en_1413-8123-csc-21-09-2797.pdf

9. Dias MF, Savassi LCM. Visita Domiciliar. Grupo de Estudos em Saúde da Família. AMMFC: Belo Horizonte, 2006.

10. Kelly L, Strasser R. Community-based medical education. London- New York: Radcliffe Publishing, 2012.

11. Vignachi CM, Benetti CS, Machado CLB, Manfroi WC Considerações sobre aprendizagem baseada em problemas na educação em saúde. Rev HCPA [Internet]. 2009 [acessado 2018 Mai 07];29(1):45-50. Disponível em: https://www.lume.ufrgs.br/handle/10183/157866

12. Cunha MI. O professor na transição de paradigmas. Araraquara: JM Editores, 1998.

13. Rogers CR. Tornar-se pessoa. São Paulo: Martins Fontes, 1997.

14. Freire P. Cartas à Cristina. Rio de Janeiro: Paz e Terra, 1994. 
15. Barreto VHL, Monteiro ROS, Magalhães GSG, Almeida RCC, Souza LN. Papel do Preceptor da Atenção Primária em Saúde na Formação da Graduação e Pós-Graduação da Universidade Federal de Pernambuco - um Termo de Referência. Rev Bras Educ Méd [Internet]. 2011 [acessado 2018 Jul 29];35(4):578-83. Disponível em: http://www.scielo.br/pdf/rbem/v35n4/a19v35n4.pdf 